\title{
Optimization Letters Best Paper Award
}

\author{
Pavlo A. Krokhmal • Oleg Prokopyev
}

Received: 21 October 2014 / Accepted: 28 October 2014 / Published online: 8 November 2014

(C) Springer-Verlag Berlin Heidelberg 2014

\section{Dear Colleagues,}

It is our pleasure to announce an annual OPTL Best Paper Award, to be given to a manuscript published in Optimization Letters during the corresponding calendar year. The Award will carry a 1,000 USD prize. This year, a total of nine papers published in OPTL during the year of 2013 were nominated for the Award and considered by the Best Paper Award Committee, which included OPTL Editorial Board members Dr. Anna Nagurney, Dr. Immanuel Bomze, and the Founding Editor-In-Chief, Dr. Panos Pardalos. Based on the recommendations of the Committee, the following paper:

Dickinson, P.J.C., Dür, M., Gijben, L., Hildebrand, R.: Scaling relationship between the copositive cone and Parrilo's first level approximation. Optim. Lett. 7(8), 1669-1679 (2013)

was named as the winner of the 2013 OPTL Best Paper Award. The Committee members have noted this work as "a very well-written paper", which is expected to make "a major impact as it will have important algorithmic consequences." In addition, the following papers received honorable mention:

Cacchiani, V., Caprara, A., Toth, P.: Finding cliques of maximum weight on a generalization of permutation graphs. Optim. Lett. 7(2), 289-296 (2013)

Polyak, R.A., Costa, J., Neyshabouri, S.: Dual fast projected gradient method for quadratic programming. Optim. Lett. 7(4), 631-645 (2013)

\footnotetext{
P. A. Krokhmal ( $\varangle)$

University of Iowa, Iowa City, IA, USA

e-mail: pavlo-krokhmal@uiowa.edu

O. Prokopyev

University of Pittsburgh, Pittsburgh, PA, USA

e-mail: prokopyev@engr.pitt.edu
} 
Žilinskas, A.: On the worst-case optimal multi-objective global optimization. Optim. Lett. 7(8), 1921-1928 (2013)

Please join us in congratulating the authors of the abovementioned papers for their excellent contributions to literature! 